\section{An increase in superoxide dismutase ameliorates oxygen- induced retinopathy in transgenic mice}

A Spierer ${ }^{1,3}$, R Rabinowitz ${ }^{2,3}$, S Pri-Chen ${ }^{1}$ and M Rosner

\author{
${ }^{1}$ Goldschleger Eye Institute \\ Sheba Medical Center \\ Tel-Hashomer \\ Sackler Faculty of Medicine \\ Tel-Aviv University \\ Tel-Aviv, Israel \\ ${ }^{2}$ Department of \\ Ophthalmology \\ Soroka University Medical \\ Center \\ Beer-Sheva, Israel
}

\section{Correspondence:}

Abraham Spierer

Goldschleger Eye Institute

Sheba Medical Center

52621 Tel-Hashomer

Israel

Tel: + 972-03-5302874

Fax: + 972-03-5302822

E-mail: spierera@

post.tau.ac.il

${ }^{3}$ These authors contributed equally to the work

Received: 4 October 2003 Accepted: 28 November 2003

Published online: 2 July 2004

\begin{abstract}
Purpose Oxygen therapy is a well-recognized risk factor for retinopathy of prematurity. We examined whether an increase in the naturally occurring enzyme copper-zinc superoxide dismutase (CuZnSOD), which controls oxygen, can reduce the severity of oxygeninduced retinopathy in a mouse model.

Methods Seven transgenic mice overexpressing CuZnSOD and six wild-type mice were exposed to $75 \%$ oxygen from postnatal day 7 to 12 . Seven transgenic mice and five mice of the wild type were kept in room air and served as controls.

Fluorescein-conjugated dextran angiography of retinal vasculature was performed and flat-mounted preparations were evaluated by scoring blood vessel growth, blood vessel tuft formation, extraretinal neovascularization, degree of central constriction, and tortuosity of vessels. In addition, quantification of the number of blood vessel tufts was performed in a masked fashion with haematoxylin and eosin staining of paraffin-embedded eye sections.

Results The mean retinal score $\pm \mathrm{SD}$ obtained by the wild-type mice was $9.4 \pm 2.0$, whereas the transgenic mice overexpressing CuZnSOD obtained a value of $2.4 \pm 1.6(P=0)$. The two control groups (wild type and transgenic) that were kept in room air, each obtained a score of 0 . Significantly fewer extraretinal vascular tufts were seen in the transgenic mice $(0.26 \pm 0.34)$ than in the wildtype mice $(4.27 \pm 1.6)$ after both groups were exposed to oxygen $(P<0.001)$.

Conclusions The results suggest that high SOD activity protects neonatal mice against oxygen-induced retinopathy, and support the
\end{abstract}

assumption that oxygen radicals are a major causative factor in oxygen-induced retinopathy.

Eye (2005) 19, 86-91. doi:10.1038/sj.eye.6701424 Published online 2 July 2004

Keywords: oxygen-induced retinopathy; superoxide dismutase; transgenic mice

Introduction

Oxygen therapy is a well-recognized risk factor for retinopathy of prematurity (ROP), a serious vasoproliferative disorder in preterm infants that can lead to severe visual impairment or blindness. Oxygen can damage developing tissue through the oxidative effect of oxygen radicals. ${ }^{1,2}$ The principal risk factors for ROP are considered to be birth weight, gestational age, and the amount and duration of supplemental oxygen..$^{3-7}$ Developing tissue can be harmed as a result of the oxidative effect of oxygen radicals, which cause damage presumably by increasing the peroxidation of fatty acids or nucleic acids and eliminating protein cross-linking. ${ }^{8}$ The multicentre trial of cryotherapy for ROP demonstrated that the risk of unfavourable outcome is $50 \%$ in 'threshold ROP' and that cryotherapy decreases this risk by nearly $35 \% .{ }^{9,10}$ Studies have shown that vitamin E might also mitigate the effect of antioxidants on ROP in humans. ${ }^{11}$

Superoxide dismutase (SOD) is a ubiquitous water-soluble enzyme known to exert antioxidant activity due to its function as a specific scavenger of the $\mathrm{O}_{2}^{-}$anion. Supplementation of SOD both in vitro ${ }^{12,13}$ and in vivo, ${ }^{14-17}$ as well as overexpression of SOD in transgenic mice, ${ }^{18-21}$ can protect against hyperoxic damage. These findings prompted us to examine whether overexpression of SOD 
would reduce the retinal vaso-attenuation, obliteration, and neovascularization caused by hyperoxia in a wellcharacterized model of ROP in transgenic mice.

\section{Methods}

\section{Animals}

Transgenic mice harbouring the human CuZnSOD gene were produced at the Weizmann Institute of Science by microinjection of fertilized eggs with a linear 14 . 5-kb fragment of human genomic DNA containing the entire $\mathrm{CuZnSOD}$ gene, including its regulatory sequences, as previously described. ${ }^{22,23}$ The TgHS-51 progeny, which we used in our experiment, contains five copies of the human CuZnSOD gene in their genome.

All mice were handled according to the ARVO statement for the Use of Animals in Ophthalmic and Vision Research and were approved by the Institutional Animal Care and Use Committee at Tel-Aviv University.

\section{Oxygen-induced retinopathy in mice}

In all, 14 transgenic CuZnSOD neonatal mice and 11 wild-type mice were used. Seven transgenic and six wild-type mice were placed with their nursing mothers in the same covered plastic box and exposed to $75 \% \pm 2 \%$ oxygen on postnatal day 7 (P7) through P12 as previously described. ${ }^{24}$ Oxygen concentration was measured with an Oxygen Monitor (Teledyne Electronic Technologies), and the delivery was checked at least three times a day during the exposure period. The mice were then returned to room air until P17. During that period, the rest of the transgenic and wild-type mice were kept, together with their nursing mothers, in room air and served as controls.

\section{Fluorescein dextran perfusion of the retinal blood vessels}

Mice were anaesthetized by intraperitoneal

administration of chloral hydrate $(360 \mathrm{mg} / \mathrm{kg})$. Through a median sternotomy, the left ventricle of the heart was identified and perfused with $0.3 \mathrm{ml}$ of fluoresceinconjugated dextran (MW 2000000; $25 \mathrm{mg} / \mathrm{ml}$; Sigma) in $4 \%$ phosphate-buffered saline (PBS; Sigma), as previously described. ${ }^{25}$ The mice were then given a lethal dose of chloral hydrate and their eyes were enucleated. The right eyes were placed in $4 \%$ paraformaldehyde (Sigma) for $24 \mathrm{~h}$. Under a dissecting microscope, the retina was removed, flat-mounted by radial cutting, and covered with a coverslip after a few drops of Pertex mounting media (CellPath) were placed on the slide. It was then viewed under a fluorescence microscope and photographed with a digital camera.
The flat-mounted preparations were independently evaluated and each retina was scored in a masked fashion by two investigators (RR and AS), using a slight modification of a published retinal scoring system. ${ }^{26}$ The parameters scored in each retina were blood vessel growth, blood vessel tuft formation, extraretinal neovascularization, degree of central constriction, and tortuosity of vessels. We used the retinopathy scoring system described by Higgins et al, ${ }^{26}$ in which each parameter is given a score ranging from 0 (normal appearance) to 3 (most severe), except for blood vessel tuft formation, which is scored from 0 to 4 . We did not allot a score for the presence of retinal haemorrhages (as used in the original retinal scoring system) because we could not assess this parameter in our flat-mounted retinal sections. The average retinopathy score obtained by the two investigators for each retina was used for the statistical analysis.

\section{Hematoxylin and eosin staining of retinal sections}

After enucleation, the left eyes were immediately placed in $1 \%$ formaldehyde and $1.25 \%$. glutaraldehyde ${ }^{27}$ (Sigma) for at least $48 \mathrm{~h}$, and then embedded in paraffin. To investigate the amount of neovascularization in the retina, we cut serial sections ( $5 \mu \mathrm{m}$ thick) in a sagittal anterior-posterior plane through the cornea, parallel to the optic disc, and stained the sections with haematoxylin and eosin. Multiple sections from individual eyes were scored under light microscopy by observers blinded to the source of the sections, who counted the vascular tufts that extended beyond the inner limiting membrane into the vitreous, as previously described. ${ }^{26}$ Six sections, $50 \mu \mathrm{m}$ apart, were evaluated and counted per eye and averaged. The mean number of tufts per section for each eye was used for the statistical analysis.

\section{Statistical analysis}

Results were analysed using Student's $t$-test or analysis of variance. Statistical significance was defined as $P<0.05$.

\section{Results}

After exposure to air containing $75 \%$ oxygen, the mean retinal score (RS) $\pm S D$ obtained by the wild-type mice $(n=6)$ was 9.4 \pm 2.0 , whereas the transgenic mice overexpressing $\mathrm{CuZnSOD}(n=7)$ obtained a value of $2.4 \pm 1.6$ (Figure 1). The difference between the groups was highly significant $(P=0)$. The two control groups (wild type, $n=5$, and transgenic, $n=7$ ) that were kept in room air each obtained a score of 0 . 
Comparison between the transgenic mice and the wild-type mice of the oxygen-treated groups showed significant differences for all subcategories tested $(P=0)$, except for blood vessel growth $(P=0.019)$ (Figure 2$)$.

The finding of excessive extraretinal neovascularization in flat-mounted retinal sections obtained from wild-type mice after their prolonged exposure to oxygen was corroborated by counting of the vascular tufts. Significantly fewer extraretinal vascular tufts were seen in the transgenic mice $(0.26 \pm 0.34)$ than in the wild-type mice $(4.27 \pm 1.6)$ after both groups were exposed to oxygen (Figure 3 ). No vascular tufts were

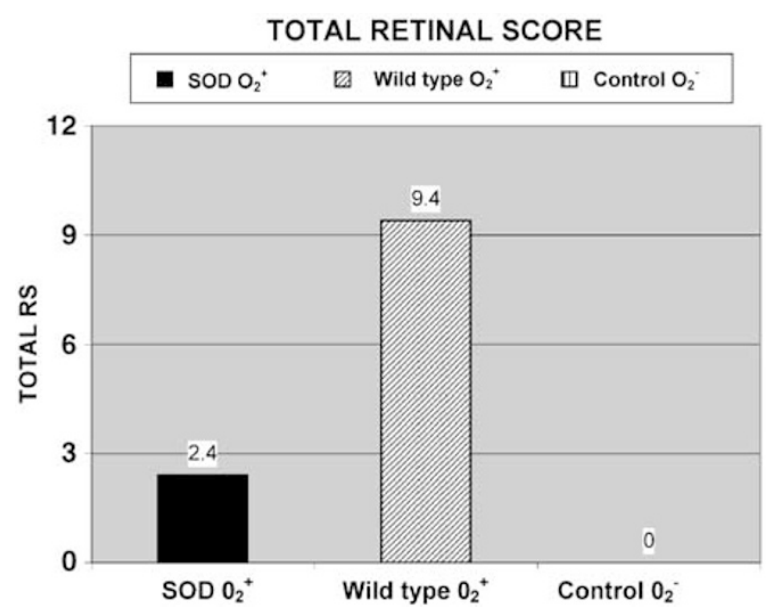

Figure 1 Total RS obtained by the modified retinopathy scoring system $^{26}$ in transgenic CuZnSOD mice and wild-type mice exposed to air containing $75 \%$ oxygen and in mice kept in room air. SOD $\mathrm{O}_{2}^{+}$: transgenic CuZnSOD mice exposed to $75 \%$ oxygen Wild-type $\mathrm{O}_{2}+$ : wild-type mice exposed to $75 \%$ oxygen. Control $\mathrm{O}_{2}^{-}$: CuZnSOD and wild-type mice kept in room air.

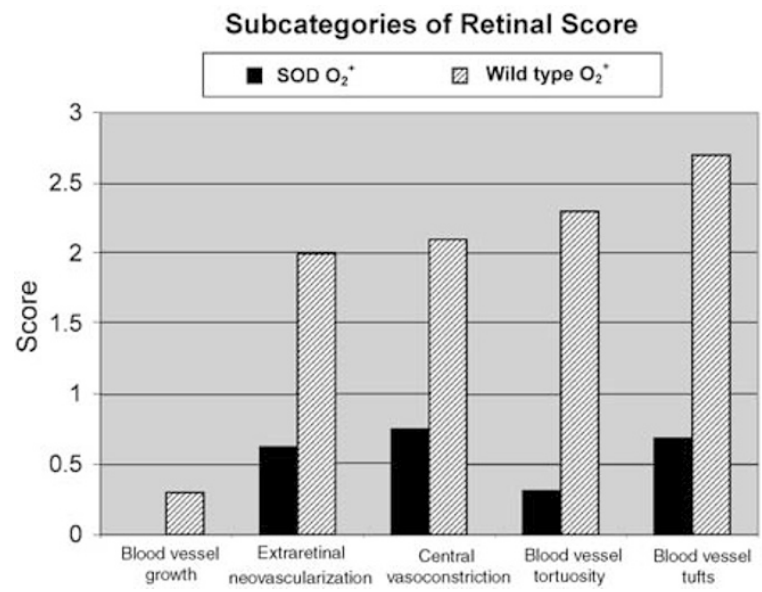

Figure 2 Subcategories of the retinopathy scoring system (RSS). Black bars represent mean values of the subcategories in transgenic CuZnSOD mice exposed to $75 \%$ oxygen . Bars with oblique lines represent mean values of the subcategories in wildtype mice exposed to $75 \%$ oxygen.

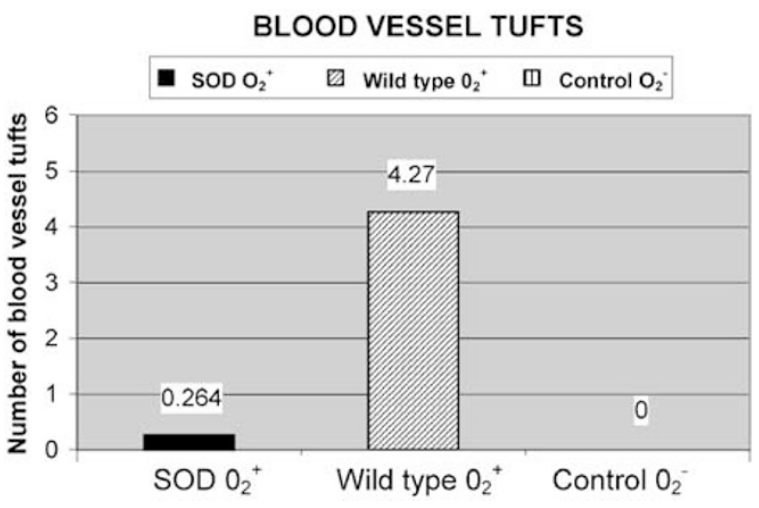

Figure 3 Extraretinal vascular tufts counted in retinal sections from transgenic $\mathrm{CuZnSOD}$ mice and wild-type mice exposed to $75 \%$ oxygen and from control groups (SOD and wild-type mice) kept in room air. SOD $\mathrm{O}_{2}^{+}$: Transgenic CuZnSOD mice exposed to $75 \%$ oxygen. Wild-type $\mathrm{O}_{2}^{+}$: Wild-type mice exposed to $75 \%$ oxygen. Control $\mathrm{O}_{2}^{-}$: CuZnSOD and wild-type mice kept in room air.

observed in either of the two control groups. Figure 4 shows the flat-mounted retina of one wild-type mouse (a) and one CuZnSOD transgenic mouse (b) that were exposed to oxygen.

\section{Discussion}

Oxidative retinal damage caused by free oxygen radicals $^{1,2}$ is one of the factors thought to play an important role in the pathogenesis of ROP. Reactive oxygen radicals may cause angiogenesis directly, or lead to it indirectly through the release of angiogenic growth factors. Hypoxic tissues, including the retina, produce vascular endothelial growth factor (VEGF) ${ }^{28-30}$ in amounts that correlate with ocular angiogenesis. ${ }^{31}$ Reactive oxygen radicals such as superoxide increase VEGF synthesis in retinal pigment epithelial cells. Inhibition of VEGF synthesis prevents ischaemiaassociated neovascularization in the primate eye. ${ }^{32} \mathrm{In}$ view of the toxic effect of oxygen radicals on the retina and their role in ROP development, any intervention that diminishes the production of oxygen radicals might reasonably be expected to decrease the severity of ROP.

Human CuZnSOD is encoded by a gene residing on chromosome 21 and is a key enzyme in the metabolism of free oxygen radicals. ${ }^{8}$

It converts superoxide radicals $\left(\mathrm{O}_{2}^{-}\right)$in to hydrogen peroxide $\left(\mathrm{H}_{2} \mathrm{O}_{2}\right)$ and oxygen, and the hydrogen peroxide is metabolized by catalase and glutathione peroxidase. The human retina is rich in these proteins. ${ }^{33-35}$

Transgenic mice of strains 218/3 and 218/10, both possessing levels of $\mathrm{CuZnSOD}$ about three times higher than those in nontransgenic mice, are partially or 

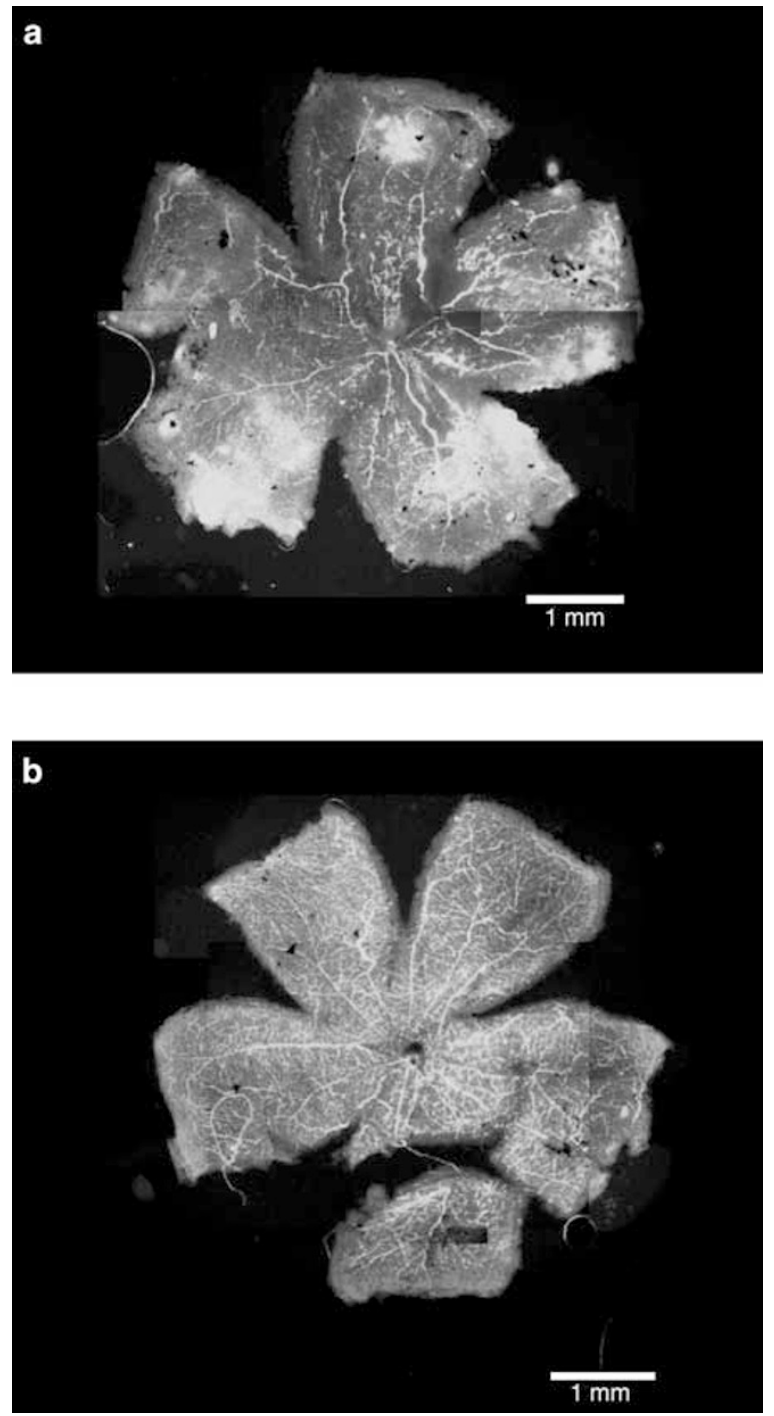

Figure 4 Representative fluorescein-conjugated dextran-perfused flat-mounted retinal preparations from (a) a wild-type mouse exposed to $75 \%$ oxygen ( $R S=10$ ), showing significant loss of central blood vessels, tortuosity of vessels, and neovascular tufts, and from (b) a transgenic CuZnSOD mouse exposed to $75 \%$ oxygen $(R S=0)$, showing a normal retina.

completely protected against the acute oxidative stress imposed by various physical and chemical agents. In the nervous system of adult mice, these sources of stress include freezing, blunt trauma, ischaemia and reperfusion, as well as injection of $N$-methyl-4-pheny1,2,3,6-tetrahydropyridine (MPTP) and methamphetamine. ${ }^{18-21,36,37}$ Sources of oxidative stress outside the nervous system include streptozotoxin, alloxan, ${ }^{38}$ and tumour necrosis factor. ${ }^{39}$ Protection against hyperoxia-related pulmonary toxicity has been documented in the same transgenic mice strain as that used in our study. ${ }^{40}$ These and related observations led us to suspect that other pathological processes in which free radicals play a role might also be ameliorated in CuZnSOD transgenic mice. In this study, we demonstrated the protective effect of CuZnSOD against oxygen-induced retinopathy in newborn mice exposed to hyperoxia. After neonatal exposure to $75 \%$ oxygen, the total retinal score and the scores for each of its subcategories were significantly better in the transgenic mice than in the wild type. These findings were substantiated by the significantly larger number of neovascular tufts seen in retinal cross-sections taken from the wild-type mice than in those from the transgenic mice. These observations support the prominent role of free oxygen radicals in the pathogenesis of oxygen-induced retinopathy and the protective effect of increased amounts of the superoxide dismutase enzyme against such retinopathy.

Our results differ from those of Klaeger et al, ${ }^{41}$ who found that a CuZnSOD activity three-fold higher than normal did not protect against oxygen-induced retinopathy in mice, an observation that the authors acknowledge was unexpected. The discrepancy between their findings and ours might be explained, firstly, by the fact that they used intermittent oxygen exposure of $12 \mathrm{~h}$ daily for 5 days, beginning immediately after birth, combined with intermittent exposure to room air, until day 16 when the mice were killed. It is possible that the intrinsic oxygen sensitivity of the mouse retinal vessels is crucially affected by the timing of supplemental oxygen, as independent studies have shown that the effect of hyperoxia on developing vessels can change dramatically as a function of age. ${ }^{24,42}$ Secondly, Klaeger et $a l^{41}$ used India ink to demonstrate the retinal vascularization, whereas we perfused the mice with fluorescein dextran, which reportedly allows better visualization of the retinal vasculature. ${ }^{26}$

Another experimental system in which increased CuZnSOD activity was not protective against oxidative damage to the retina was described by Smith et al, ${ }^{43}$ who reported that transgenic mice with a two-fold increase in SOD activity, used as a model for oxygen-induced retinopathy, showed an increase in retinal neovascularization. These authors also found no difference between the area of hypoxia-induced vascular obliteration in the SOD transgenic mice and the wild type. The CuZnSOD activity in our transgenic mice, determined in primary cell cultures as well as in brain extracts, was four times greater than in the wild type. ${ }^{44}$ This large variation in CuZnSOD overexpression between our study and that of Smith et al ${ }^{43}$ might well account for the difference in the observed protective effects of overexpression of CuZnSOD on oxygeninduced retinopathy.

The use of laser or cryotherapy has greatly improved the treatment of ROP. Nevertheless, a therapy that could 
prevent ROP development would represent a substantial advance. This study supports the theory that antioxidants such as CuZnSOD might play an important role in the prevention of retinal vascular formation caused by exposure to high concentrations of oxygen. Further research is needed before these findings can be harnessed for the development of a preventive treatment for premature infants at risk of ROP.

\section{Acknowledgements}

We thank Y Groner of The Weizmann Institute of Science, Rehovot, Israel for providing the mice for this study. This project was supported by a Maratier grant from the Sackler Faculty of Medicine, Tel-Aviv University, Tel-Aviv, Israel.

\section{References}

1 Phelps DL. Retinopathy of prematurity. Curr Probl Pediatr 1992; 22: 349-371.

2 Katz ML, Robison Jr WG. Autoxidative damage to the retina: potential role in retinopathy of prematurity. Birth Defects Orig Artic Ser 1988; 24: 237-248.

3 Kinsey VE, Arnold HJ, Kaliana RE, Stern L, Stahlman M, Odell $\mathrm{G}$ et al. $\mathrm{PaO}_{2}$ levels and retrolental fibroplasias: a report of the cooperative study. Pediatrics 1977; 60: 655-668.

4 Gunn TR, Easdown J, Outerbridge EW, Aranda JV. Risk factors in retrolental fibroplasia. Pediatrics. 1980; 65: 1096-1100.

5 Shahinian Jr L, Malachowski N. Retrolental fibroplasia: a new analysis of risk factors based on recent cases. Arch. Ophthalmol. 1978; 96: 70-74.

6 Flynn JT, Bancalari E, Bachynski B, Buckley EB, Bawol R, Goldberg R et al. Retinopathy of prematurity. Diagnosis, severity, and natural history. Ophthalmology 1987; 94: 620-629.

7 Quinn GE, Johnson L, Abbasi S. Onset of retinopathy of prematurity as related to postnatal and postconceptional age. Br J Ophthalmol 1992; 76: 284-288.

8 Cheeseman $\mathrm{KH}$, Slater TF. An introduction to free radical biochemistry. Br Med Bull 1993; 49: 481-493.

9 Multicenter trial of cryotherapy for retinopathy of prematurity. Snellen visual acuity and structural outcome at $51 / 2$ years after randomization. Cryotherapy for Retinopathy of Prematurity Cooperative Group. Arch Ophthalmol 1996; 114: 417-424.

10 Multicenter Trial of Cryotherapy for Retinopathy of Prematurity: ophthalmological outcomes at 10 years. Arch Ophthalmol 2001; 119: 1110-1118.

11 Raju TN, Langberger P, Bhutani V, Quinn GE. Vitamin E prophylaxis to reduce retinopathy of prematurity: a reappraisal of published trials. J Pediatr 1997; 131: 844-850.

12 Freeman BA, Young SL, Crapo JD. Liposome-mediated augmentation of superoxide dismutase in endothelial cells prevents oxygen injury. J Biol Chem 1983; 258: 12534-12542.

13 Nakae D, Yoshiji H, Amanuma T, Kinugasa T, Farber JL, Konishi Y. Endocytosis-independent uptake of liposomeencapsulated superoxide dismutase prevents the killing of cultured hepatocytes by tert-butyl hydroperoxide. Arch Biochem Biophys 1990; 279: 315-319.

14 Chan PH, Longar S, Fishman RA. Protective effects of liposome-entrapped superoxide dismutase on posttraumatic brain edema. Ann Neurol 1987; 21: 540-547.

15 Stanimirovic DB, Markovic M, Micic DV, Spatz M, Mrsulja BB. Liposome-entrapped superoxide dismutase reduces ischemia/reperfusion oxidative stress in gerbil brain. Neurochem Res 1994; 19: 1473-1478.

16 Imaizumi S, Woolworth V, Fishman RA, Chan PH. Liposomeentrapped superoxide dismutase reduces cerebral infarction in cerebral ischemia in rats. Stroke 1990; 21: 1312-1317.

17 Senga S, Onituka A, Hirose H, Yamamoto K, Niwa K. Protective effect of liposome encapsulated superoxide dismutase on ischemically injured liver in the rat. Transplant Proc 1990; 22: 2025-2026.

18 Chan PH, Yang GY, Chen SF, Carlson E, Epstein CJ. Coldinduced brain edema and infarction are reduced in transgenic mice overexpressing $\mathrm{CuZn}$-superoxide dismutase. Ann Neurol 1990; 29: 482-486.

19 Kinouchi H, Epstein CJ, Mizui T, Carlson E, Chen SF, Chan $\mathrm{PH}$. Attenuation of focal cerebral ischemia injury in transgenic mice overexpressing $\mathrm{CuZn}$ superoxide dismutase. Proc Natl Acad Sci USA 1991; 88: 11158-11162.

20 Przedborski S, Kostic V, Jackson-Lewis V, Naini AB, Simonetti S, Fahn $S$ et al. Transgenic mice with increased $\mathrm{Cu} / \mathrm{Zn}$-superoxide dismutase activity are resistant to $\mathrm{N}$ methyl-4-phenyl-1,2,3,6-tetrahydropyridine-induced neurotoxicity. J. Neurosci. 1992; 12: 1658-1667.

21 Cadet JL, Sheng P, Ali S, Rothman R, Carlson E, Epstein C. Attenuation of methamphetamine-induced neurotoxicity in copper/zinc superoxide dismutase transgenic mice. $J$ Neurochem 1994; 26: 380-383.

22 Epstein CJ, Avraham KB, Lovett M, Smith S, Elroy-Stein O, Rotman $\mathrm{G}$ et al. Transgenic mice with increased $\mathrm{Cu} / \mathrm{Zn}$ superoxide dismutase activity: animal model of dosage effects in Down syndrome. Proc Natl Acad Sci USA 1987; 84(22): 8044-8048.

23 Avraham KB, Schickler M, Sapoznikov D, Yarom R, Groner Y. Down's syndrome: abnormal neuromuscular junction in tongue of transgenic mice with elevated levels of human $\mathrm{Cu} / \mathrm{Zn}$-superoxide dismutase. Cell 1988; 54: 823-829.

24 Smith LEH, Weselowski E, McLellan A, Kostyk SK, D'Amato R, Sullivan R et al. Oxygen-induced retinopathy in the mouse. Invest. Ophthalmol. Vis. Sci. 1994; 35: 101-111.

25 D'Amato R, Wesolowski E, Smith LEH. Microscopic visualization of the retina by angiography with highmolecular-weight fluorescein-labeled dextrans in the mouse. Microvasc Res 1993; 46: 135-142.

26 Higgins RD, Yu K, Sanders RJ, Nandgaonkar BN, Rothchild $\mathrm{T}$, Rifkin DB. Diltiasem reduces retinal neovascularization in a mouse model of oxygen induced retinopathy. Curr Eye Res 1999; 18: 20-27.

27 Curtis EM, Amy L. Fixation of whole eyes: the role of fixative osmolarity in the production of tissue artifact. Graefe's Arch Clin Exp Ophthalmol 1995; 233: 366-370.

28 Namiki A, Brogi E, Kearney M, Kim EA, Wu T, Couffinhal T et al. Hypoxia induces vascular endothelial growth factor in cultured human endothelial cells. J Biol Chem 1995; 270 : 31189-31195.

29 Stone J, Chan-Ling T, Pe'er J, Itin A, Gnessin H, Keshet E. Roles of vascular endothelial growth factor and astrocyte degeneration in the genesis of retinopathy of prematurity. Invest Ophthalmol Vis Sci 1996; 37: 290-299. 
30 Shima DT, Adamis AP, Ferrara N, Yeo KT, Yeo TK, Allende $\mathrm{R}$ et al. Hypoxic induction of endothelial cell growth factors in retinal cells: identification and characterization of vascular endothelial growth factor (VEGF) as the mitogen. Mol Med 1995; 1: 182-193.

31 Miller JW, Adamis AP, Shima DT, D'Amore PA, Moulton RS, O'Reilly MS et al. Vascular endothelial growth factor/ vascular permeability factor is temporally and spatially correlated with ocular angiogenesis in a primate model. Am J Pathol 1994; 145: 574-584.

32 Adamis AP, Shima DT, Tolentino MJ, Gragoudas ES, Ferrara $\mathrm{N}$, Folkman J et al. Inhibition of vascular endothelial growth factor prevents retinal ischemia-associated iris neovascularization in a nonhuman primate. Arch Ophthalmol 1996; 114: 66-71.

33 Newsome DA, Dobard EP, Liles MR, Oliver PD. Human retinal pigment epithelium contains two distinct species of superoxide dismutase. Invest Ophthalmol Vis Sci 1990; 31: 2508-2513.

34 Naash MI, Nielsen JC, Anderson RE. Regional distribution of glutathione peroxidase and glutathione-S-transferase in adult and premature human retinas. Invest Ophthalmol Vis Sci 1988; 29: 22-26.

35 Atalla L, Fernandez MA, Rao NA. Immunohistochemical localization of catalase in ocular tissue. Curr Eye Res 1987; 6: 1181-1187.

36 Murakami K, Kondo T, Epstein CJ, Chan PH. Overexpression of $\mathrm{CuZn}$ - superoxide dismutase reduces hippocampal injury after global ischemia in transgenic mice. Stroke 1997; 28: 1797-1804.

37 Sheng H, Bart RD, Oury TD, Pearlstein RD, Crapo JD, Warner DS. Mice overexpressing extracellular superoxide dismutase have increased resistance to focal cerebral ischemia. Neuroscience 1999; 88: 185-191.

38 Kubisch HM, Wang J, Luche R, Carlson E, Bray TM, Epstein CJ et al. Transgenic copper/zinc superoxide dismutase modulates susceptibility to type É diabetes. Proc Natl Acad Sci USA 1994; 91: 9956-9959.

39 Sakashita A, Epstein CJ, Carlson E, Koeffler HP. Hematopoietic progenitor cells of transgenic mice with increased copper/zinc-superoxide dismutase activity are resistant to tumor necrosis factor. J Cell Physiol 1994; 160: 233-238.

40 White CW, Avraham KB, Shanley PF, Groner Y. Transgenic mice with expression of elevated levels of copper-zinc superoxide dismutase in the lungs are resistant to pulmonary oxygen toxicity. J Clin Invest 1991; 87: 2162-2168.

41 Klaeger C, de Sa L, Klaeger AJ, Carlson EJ, Good WV, Epstein CJ. An elevated level of copper zinc superoxide dismutase fails to prevent oxygen induced retinopathy in mice. Br J Ophthalmol 1996; 80: 429-434.

42 Gu X, Samuel S, El-Shabrawey M, Caldwell RB, Bartoli M, Marcus DM et al. Effects of sustained hyperoxia on revascularization in experimental retinopathy of prematurity. Invest Ophthalmol Vis Sci 2002; 43: 496-502.

43 Smith LEH, Freedman SF, Foley ED, McLellan A, Schwartz $\mathrm{P}$. The effect of overexpression of $\mathrm{Cu} / \mathrm{Zn}$ superoxide dismutase on oxygen-induced retinopathy in a transgenic mouse. Invest Ophthalmol Vis Sci 1994; 45(suppl): 1442.

44 Minc-Golomb D, Knobler H, Groner Y. Gene dosage of CuZnSOD and Down's syndrome: diminished prostaglandin synthesis in human trisomy 21, transfected cells and transgenic mice. EMBO J 1991; 10: 2119-2124. 